\title{
Bullying and Victimization in Native and Immigrant Very-Low-Income Adolescents in Italy: Disentangling the Roles of Peer Acceptance and Friendship
}

\author{
Dora Bianchi ${ }^{1}$ - Elisa Cavicchiolo ${ }^{2}$ (D) - Sara Manganelli ${ }^{3} \cdot$ Fabio Lucidi $^{1} \cdot$ Laura Girelli $^{2}$. \\ Mauro Cozzolino ${ }^{2} \cdot$ Federica Galli $^{1} \cdot$ Fabio Alivernini ${ }^{1}$
}

Accepted: 23 March 2021 / Published online: 6 April 2021

(C) The Author(s) 2021

\begin{abstract}
Background Very-low-income students are a population at a high risk of perpetrating and suffering bullying at school, and at the same time the peer group at school is often one of the few sources of support for these minors.

Objective This two-wave study is aimed to disambiguate the two different roles of peer acceptance and friendship on bullying and victimization in very-low-income adolescents, exploring the possible differential role of immigrant background.

Method An online survey was administered to 249 early to late adolescents living below the poverty threshold $\left(M_{\text {age }}=12.76 ; S D_{\text {age }}=2.34 ; 41.8 \%\right.$ girls; $19.3 \%$ immigrants $)$. A multivariate regression model with multi-group analyses was applied.

Results Our results indicated that peer friendship was a protective factor against bullying as well as victimization, whilst peer acceptance was not protective. Only for natives (but not for immigrants), a high level of peer acceptance was a risk factor for bullying, and low school achievement was a risk factor for victimization. The persistence of victimization over time was significantly stronger for immigrants than for natives.

Conclusions The study provides new insights for the unique protective role of classmates' friendship in natives and immigrants, while acceptance appeared to be less relevant. Research and applied implications are discussed.
\end{abstract}

Keywords Bullying $\cdot$ Victimization $\cdot$ Peer friendship $\cdot$ Peer acceptance $\cdot$ Immigrants

Elisa Cavicchiolo

ecavicchiolo@unisa.it

1 Department of Developmental \& Social Psychology, Sapienza University of Rome, Via dei Marsi 78 , Rome, Italy

2 Department of Human, Philosophical and Educational Sciences, University of Salerno, Via Giovanni Paolo II, 132 Fisciano, Salerno, Italy

3 National Institute for the Evaluation of the Education System (INVALSI), Via Ippolito Nievo 35, Rome, Italy 


\section{Introduction}

Students living below the poverty threshold are at a high risk for perpetrating and suffering bullying in all grades of school (Tippett \& Wolke, 2014). The frequent victimization of these students by their peers has been related to the stigmatization for their being "different" due to familial poverty, and/or to the poor relational skills of minors raised in highly deprived environments (Seo et al., 2017; Tippett \& Wolke, 2014). There is also increasing evidence about the higher prevalence of bullying behaviors in students living in poverty (Hong, Choi et al., 2020; Hong, Kim et al., 2020; Malecki et al., 2020), who may bully their peers as a reaction to the suffered stigmatization, or to combat feelings of low selfesteem (Dietrich \& Ferguson, 2020). Overall, the nature of the associations between poverty and school bullying is still unclear, and the contrasting results of previous research are due to the very different measures of socio-economic status (SES) adopted (metanalysis by Tippett \& Wolke, 2014). It seems necessary to conduct studies more specifically focused on populations living in poverty, as the extant literature has generally taken conditions of social and economic disadvantage into account, but the dynamics of bullying have never been investigated in groups characterized by persistent poverty.

The present study therefore set out to investigate the specific patterns of bullying within a population consisting exclusively of adolescents living below the poverty threshold, namely "very low-income" in this study. The poverty threshold in Italy is computed as an income equal to the minimum expenditure required to purchase the goods and services considered essential, in the Italian context, for attaining the minimum acceptable standard of living (Vecchiato, 2015). According to the most recent national reports (National Institute of Statistics, ISTAT, 2020), the $6.4 \%$ of families, and the $11.4 \%$ of minors in Italy live in conditions of poverty.

The extant literature underlined the core role of peer support in contrasting school bullying and protecting victims from negative developmental outcomes (Cowie, 2011; Flaspohler et al., 2009; Tzani-Pepelasi et al., 2019). In the light of previous studies on the role of peers in bullying dynamics (Gini et al., 2015; Saarento \& Salmivalli, 2015), our study explored the different effects of peer acceptance and peer friendship on bullying perpetration and victimization among very-low-income early to late adolescents, with the expectation that some very specific results would be obtained for this population. For minors from very-low-income families, frequently exposed to stressful family environments and poor parenting in unsafe neighborhoods (Conger et al., 2010), positive peer relationships at school can be one of the very few sources of social support. The influence of classmates could thus be more relevant for the school adjustment of these students, in comparison with their more advantaged peers, perhaps even overcoming the effects of other potential risk factors, with decisive consequences on the dynamics of bullying. However, as previously mentioned, specific studies on this target population are still lacking. Moreover, the distinct effects of peer acceptance and peer friendship have rarely been compared in literature on bullying, as most studies have focused either on one or the other (de Bruyn et al., 2010; Kendrick et al., 2012). Thus, this study is also the first attempt to distinguish the different roles of acceptance and friendship among classmates, in predicting bullying and victimization.

Among very-low-income adolescents, immigrants can be considered as a group that is even more at risk of peer victimization due to their double minority condition, since they are both non-natives and living in extreme poverty (Chen et al., 2006; Hong et al., 2014). Immigrant families are generally more likely to live in poverty than native ones (Chaudry 
\& Fortuny, 2010), and about the $27 \%$ of immigrants in Italy live below the poverty thresholds, versus the $5.9 \%$ of Italian citizens (ISTAT, 2020). Considering the steadily increasing number of very-low-income immigrant minors in Italian schools (Foundation for Initiatives and Studies on Multi-Ethnicity, ISMU, 2020; Ministry of Education, Universities and Research, MIUR, 2019), it becomes important to understand the dynamics of bullying and victimization in this highly vulnerable group. Italy has indeed a very recent history of mass immigration, and Italian schools are often unprepared to sustain the social and cultural integration of foreign students (Milione, 2011), who frequently suffer victimization and social isolation by their native peers (Palladino et al., 2020; Pistella, Baumgartner et al., 2020; Pistella, Zava et al., 2020) and have higher levels of psychological distress (Alivernini et al., 2019c; Cozzolino et al., 2020).

Recent studies have revealed that immigrants are more subject to mixed attitudes than their native classmates (Alivernini et al., 2019b; Cavicchiolo et al., 2019) and that they may be subjected to discrimination and school violence specifically due to their immigrant background (Caravita et al., 2020; Maynard et al., 2016; Palladino et al., 2020). Moreover, immigrant students are more frequently victimized for their low socioeconomic status (Hong et al., 2014). The negative prejudices against immigrants -by peers, teachers and school officials- are a relevant risk factor (Hong et al., 2014; Peguero, 2012). As regards bullying perpetration, there is no clear evidence that immigrant students (vs. natives) are more likely to become bullies (Hong \& Espelage, 2012). However, some research has suggested that peer group dynamics may lead to very different bullying patterns for immigrants, who are more likely to bully their peers in very disadvantaged social groups (Albdour \& Krouse, 2014; Celia, 2020; Walsh et al., 2016), in absence of adequate social support (Cui \& To, 2019), or in reaction to a perceived rejection by their peers (Fandrem et al., 2009; Strohmeier et al., 2012).

Also in this area very few studies have been conducted and the predictors of bullying and victimization in immigrant very-low-income adolescents are still largely undetermined. The present study therefore aims to investigate the predictors of school bullying and victimization for the first time in a population of very-low-income adolescents, with the purpose of disambiguating the different roles of peer acceptance and friendship, and hypothesizing the presence of different patterns for immigrants and natives. The following sections present a brief review of the recent literature about school bullying and its relationships with peer acceptance and friendship.

\section{Bullying and Victimization at School}

Bullying is a major problem worldwide, showing a prevalence of $10-30 \%$ across different countries (Eslea et al., 2004), which has been substantially confirmed in the Italian context (Menesini \& Nocentini, 2015). However some studies indicated that bullying in Italy has decreased over time, as a consequence of the growing political and educational attention (Vieno et al., 2015), suggesting the importance of continuing to study this phenomenon. School bullying refers to repeated, intentional aggressive behaviors enacted by a student, or a group of students, toward a victim who cannot easily defend him/herself (Olweus, 1993; Smith \& Brain, 2000). Research has indicated that boys usually perpetrate more direct aggression, while girls engage more often in relational and indirect aggression (reviews by Hong \& Espelage, 2012; Menesini \& Salmivalli, 2017). As regard age, bullying is relatively stable over time (Cook et al., 2010), but some studies suggested that it has a peak in middle school years, whilst decreasing later during high school (Hymel \& 
Swearer, 2015; Scheithauer et al., 2006). Regarding individual risk factors, bullies tend to have positive attitudes toward aggression, and to be narcissist and lacking of empathy, but they are also competent in reaching social goals, being popular among peers and socialdominance oriented (Fanti \& Kimonis, 2012; Reijntjes et al., 2016; Van Noorden et al., 2016). Their victims instead tend to have some characteristics of vulnerability that make them more exposed to aggressions -such as internalizing problems, interpersonal difficulties, and low achievement at school (Cook et al., 2010; Menesini \& Salmivalli, 2017). Bullying may have severe negative consequences on the short and long-term mental wellbeing of all the minors involved (Bao et al., 2020; Chai et al., 2020; Menesini \& Salmivalli, 2017), and programs for prevention and early intervention are therefore of primary importance. In order to protect the most vulnerable students it is also important to detect groupspecific risk factors.

A specific form of bullying which has increasingly been the focus of studies in the last decade is the bias-based bullying, which is based on discrimination and prejudice regarding certain characteristics of the victim's identity, such as race, ethnicity, socioeconomic status, or other minority conditions (Juvonen \& Graham, 2014). Students from very-lowincome families can be considered as particularly at risk for bias-based bullying, since they are more frequently victimized due to their low social status (Tippett \& Wolke, 2014), and are more likely to bully their peers as a reaction to this kind of stigmatization, or as a consequence of the behavioral problems that are frequent in these adolescents (Ackerman et al., 2004; Dietrich \& Ferguson, 2020).

The extant literature has generally indicated that poverty may be a risk factor for bullying dynamics both at individual and at school level. At individual level, students living in poverty are more frequently victims, as well as perpetrators, of bullying (Hong, Choi et al., 2020; Hong, Kim et al., 2020), and more likely to be involved in all active bullying roles, than their not disadvantaged peers (Malecki et al., 2020). At school level, the higher prevalence of students living in poverty contributes to develop an unsafe school climate, and is associated with more bullying and victimization at school (Bradshaw et al., 2009; Malecki et al., 2020). However, some authors have suggested that not poverty by itself, but the perceived economic disparities between students-i.e. prevalence of inequality — can be at the route of bullying behaviors at school (Attree, 2006; Chaux et al., 2009).

As regards very-low-income immigrant students, they are at a higher risk than natives for being victimized at school, since they are in a double minority condition (Maynard et al., 2016). Literature about bias-based bullying has suggested that immigrant students are victimized for their ethnic origins (Peguero \& Popp, 2012; Peguero et al., 2011), but also for their frequent low-income status (Hong et al., 2014). Overall, the school climate seems to have a relevant role: peers, teachers and school officials may share the beliefs that immigrant students would have difficulties with language and learning, conduct and relational problems, and that they will be an obstacle for teaching (Olsen, 2008; SuárezOrozco et al., 2008). These negative beliefs may favor immigrants' victimization from their peers, and may also lead school personal to undervalue bullying incidents involving these students (Hong et al., 2014; Peguero, 2012). Regarding the Italian context, there is growing evidence that immigrants are more frequently victimized than natives in all grades of schools (Alivernini et al., 2019d; Palladino et al., 2020; Pistella, Baumgartner et al., 2020; Pistella, Zava et al., 2020), and that peer racial prejudice is specifically associated with the victimization of immigrant students in Italian schools (Caravita et al., 2020).

Conversely, there is as yet very little data on the predictors of bullying perpetration in very-low-income immigrant students, but some findings have suggested that immigrant adolescents may bully their peers in specific negative conditions, associated to their 
attempts to achieve peer acceptance, and in some very marginalized and disadvantaged social groups (Albdour \& Krouse, 2014; Walsh et al. 2016). The very limited evidence from Italy suggests that immigrant and native students in Italian schools show similar rates of bullying behaviors (Alivernini, Manganelli et al., 2019d), however these findings did not focus on very-low-income minors, and neglect the observation of the relational context in which bullying occur. Therefore, further studies are needed in this direction. Overall, it is acknowledged that very-low-income immigrants are more victimized than natives, whereas there is still a gap in literature about the possible risk factors which may lead very-lowincome immigrants (vs. natives) to bully their peers, and the specific relational functioning of these students still remains unexplored.

\section{The Role of Peer Relationships at School in Bullying and Victimization}

In the context of a socio-ecological framework (Bronfenbrenner, 1994), school bullying has been conceived as a group phenomenon, influenced by social relationships within the peer group (Espelage \& Swearer, 2010). The group dynamics of the class may influence the arising and maintenance of bullying, either reducing or increasing the chances that certain individuals become victims or aggressors (Gini et al., 2015), but also being determinant in sanctioning or reinforcing bullying behaviors (Saarento \& Salmivalli, 2015). Peers are a fundamental source of social support during development and, in the school context, the peer network may provide emotional, instrumental and motivational support (Alivernini et al., 2016; Malecki \& Demaray, 2003). The perceived peer support sustains a positive development in different domains, improving school achievement and self-esteem, and reducing depression and mental health problems (Colarossi \& Eccles, 2003; Domagala-Zysk, 2006). Peers social support has also a relevant role in contrasting negative developmental outcomes, protecting well-being in front of adverse conditions and stressful life events (Birkeland et al., 2014; Ezzell et al., 2000). In fact, peer support at school has proven efficacy in contrasting bullying incidents, protecting victimized students and improving their well-being (Flaspohler et al., 2009; Girelli et al., 2018). Anti-bullying programs at school are often focused on the peer support as a strategy of prevention and intervention (see for example Cowie, 2011; Tzani-Pepelasi et al., 2019). Stemming from this theoretical background, it would be reasonable to expect peer relationships at school to be even more important for the vulnerable group of very-low-income students, which often lack support in their family environments (Conger et al., 2010). However, research evidence in this direction is still lacking.

Peer relationships at school can be conceptualized in different dimensions and, among them, acceptance and friendship represent two central aspects of social inclusion in the peer group (Alivernini, Cavicchiolo et al., 2019a; Cavicchiolo et al., 2020). Acceptance refers to the individual's perceived level of inclusion within the group, and can be measured by the numbers of social interactions with classmates at school (Bierman, 2004). Friendship is instead a closer relationship, which involves frequent contacts with classmates also outside the context of school (Hall, 2019). During preadolescence and adolescence, friendship is characterized by increasing intimacy and mutual help behaviors, with several positive effects on developmental outcomes (Berndt, 2002).

Both peer acceptance and peer friendship have been shown to have important, although rather complex, relationships with school victimization and bullying. As regards the role of peer acceptance for the victims, it seems that rejected and socially isolated students tend to be victimized more frequently (de Bruyn et al., 2010; Hong \& Espelage, 2012), whereas 
higher levels of peer acceptance have a protective role (Cook et al., 2010; Demaray \& Malecki, 2003), lowering the risk of victimization also for the more vulnerable individuals (Monopoli et al., 2020). As explained by Veenstra et al., (2010), bullies tend to choose as their victims students who are less likely to be defended by other relevant peers.

The role of acceptance in bullying perpetration is more complex, since bullies may have either high or low levels of peer acceptance (Mapes et al., 2020). They are usually more popular but less liked by peers, in comparison to students who are not involved in bullying dynamics (Pouwels et al., 2016). Bullies also have high social achievement goals, and they strive to demonstrate their social competence within the peer group (Bardach et al., 2020). Other studies have indicated that bullies are only rejected by those peers who see them as a possible threat (Veenstra et al., 2010). Overall, these studies suggest that the associations between peer acceptance, victimization and bullying are highly complex, and they will require further attention in research.

On the other hand, several different studies have found that peer friendship consistently predicts lower levels of victimization (Kendrick et al., 2012; Kochel et al., 2015), indicating that having good peer relationships and supportive friends is an important protective factor. The victims of bullying are usually more isolated and have few friends at school (Eslea et al., 2004). However, according to some other studies, peer friendship may not protect from victimization the students who manifest internalizing symptoms (Bollmer et al., 2005), suggesting the existence of more complex associations which still need to be explored.

Conversely, the associations between friendship and bullying perpetration are less evident. Some studies have found that having supportive friends may predict less bullying over time (Kendrick et al., 2012), and that having friendships may reduce bullying behaviors in at-risk individuals (Bollmer et al., 2005). However other evidence has shown that the affiliation with friends who have pro-bullying attitudes may become a risk factor for an increase in bullying, due to the norms of the peer group (Cook et al., 2010). Thus, friendship may have a role that is either protective or detrimental, since positive peer influences may inhibit bullying behaviors, whereas affiliation with deviant peers may encourage them (Espelage et al., 2003).

According to the friendship protection hypothesis (Boulton et al., 1999) peer friendship is a resilience factor which may protect adolescents from negative developmental outcomes, even in the case of vulnerable individuals or negative conditions. The experience of supportive friendships encourages the development of positive social skills, and increases self-esteem, self-confidence, and psychosocial adjustment (Antonopoulou et al., 2019; Boulton et al., 1999). All of this makes young people less likely to be the victims of bullying, but also less likely to perpetrate it themselves. Conversely, bullying is positively related to friendships with aggressive or antisocial peers, that may exacerbate antisocial tendencies (Hong \& Espelage, 2012). On the whole, the literature suggests that the associations between peer friendship, school bullying and victimization are very complex, that they are moderated or enhanced by different vulnerabilities factors, and that they require further investigation, especially in the context of specific at-risk groups.

The socio-ecological approach applied to bullying (Espelage \& Swearer, 2010; Hong $\&$ Espelage, 2012) suggests that the influence of the peer network could be particularly important when the protective roles of family and community are reduced. For very-lowincome students, peer relationships at school could be one of the very few sources of social support, in the absence of adequate familial security and care (Conger et al., 2010). Therefore, despite the very complex associations between peer relatedness and bullying that have been revealed in the general population (Cook et al., 2010; Hong \& Espelage, 2012; 
Menesini \& Salmivalli, 2017), we can hypothesize that for very-low-income students peer acceptance and peer friendship could have a crucial protective role.

Within the specific group of very-low-income students, the peer context could play a different role for very-low-income immigrants. The discrimination suffered by immigrant students (Caravita et al., 2020; Palladino et al., 2020; Plenty \& Jonsson, 2017) may explain the specific protective or detrimental effects of peers on their school adjustment. Some studies have shown that the victimization of immigrant students is predicted by peer rejection (Strohmeier et al., 2011) and prevented by peer support (Walsh et al., 2016), but also that immigrants are more likely to behave as bullies as a reaction to perceived rejection, and as a means for obtaining affiliation to the peer group (Fandrem et al., 2009; Strohmeier et al., 2012), whereas conversely natives engage in bullying predominantly to affirm their social dominance within the group (Reijntjes et al., 2016).

\section{The Current Study}

The primary aim of this study is to distinguish the different roles of peer acceptance and peer friendship in school bullying and victimization, in a population of very-low-income early to late adolescents. Even if some research has been conducted on the effects of poverty on school bullying (Tippett \& Wolke, 2014), the specific patterns of bullying and victimization in students living in conditions of poverty are still unknown. Our study therefore intends to clarify the predictors of bullying in a population of adolescents officially certified as living below the poverty threshold, in order to detect the specific protective and risk factors for this population. The second aim of the present study is more explorative in nature. Since the studies on ethnic bullying have suggested the existence of specific patterns of victimization for immigrants (Palladino et al., 2020), we want to explore the possible differences in the hypothesized model between natives and immigrants. Thus, we aim to verify the following research hypotheses:

H 1) We specifically expect that peer relationships at school could have a crucial protective role against bullying and victimization in very low income adolescents, because peers are often one of the very few sources of social support for these minors, due to the frequent lack of familial support (Conger et al., 2010).

H 2) We hypothesize that friendship would have a stronger protective role than acceptance in bullying, as well as in victimization, in line with the friendship protection hypothesis (Boulton et al., 1999; Kendrick et al., 2012). To the best of our knowledge, the prospective associations of peer acceptance and peer friendship have never been simultaneously explored in previous studies on bullying, and it is currently difficult to distinguish their respective effects in the dynamics of bullying.

H 3) We also hypothesized that peer acceptance would contrast bullying perpetration in immigrant students, whereas the same variable could be a risk factor increasing bullying in natives. The few studies conducted on bullying perpetration among natives and immigrants (Cui \& To, 2019; Fandrem et al., 2009; Strohmeier et al., 2012) have suggested indeed that immigrant students tend to bully as an attempt to obtain more acceptance, because they perceive to be rejected by the group, while conversely natives do so mostly in order to affirm their dominance within the peer group.

In addition, the possible confounding effects of biological sex and school achievement on bullying and victimization were also controlled for in our models, in reason of previous findings. There is evidence indeed that boys are victimized more frequently than girls, especially during middle adolescence (Smith et al., 2019). Moreover, boys (vs. girls) more 
frequently enact bullying behaviors, showing a higher tendency to retaliation (Bradshaw et al., 2009; Smith et al., 2019). As regard school achievement, its effects on bullying and victimization are well-known, albeit to some extent conflicting (see Farrington \& Baldry, 2010 for a review). It is acknowledge that low academic performance may be a risk factor for victimization (Lehman, 2014; Nansel et al., 2001), however sometimes very high grades at school may be a risk factor as well (Lehman, 2014; Peguero \& Williams, 2013). Moreover, bullies have generally low school achievement (Nansel et al., 2001), but some authors found that higher academic achievement is also predictive of bullying behaviors (Woods \& Wolke, 2004). Finally, on the basis of the evidence for the increase of bullying dynamics during middle school years, and their decrease during the high school (Hymel $\&$ Swearer, 2015; Scheithauer et al., 2006), the possible differences between early adolescents — attending middle school — and middle to late adolescents—attending high school— were also tested in the hypothesized model.

\section{Method}

\section{Participants and Procedures}

The participants in this study were early to late adolescents from the 6th to the 13th grade, who attended educational centers for socio-economically disadvantaged minors, located in urban and suburban areas of different cities in northern, central and southern Italy. These educational centers in Italy are social support services for disadvantaged minors, offering after-school afternoon recreational and educational activities to low-income students from different schools in the local school district, while being independent from the schools themselves. Nine centers were involved in the research, from nine different Italian cities.

As a necessary inclusion criterion, all participants were from families certified as being below the poverty thresholds, according to the Italian official index of family income (Equivalent Economic Situation Indicator-ISEE). The participants completed an online survey administered in the educational centers under the supervision of trained researchers, who ensured the complete anonymity and standardization of research procedures. Before taking part in the study, all the participants and their parents provided their written informed consent.

Data were gathered in two waves at an interval of 6 months: At the baseline (time 1, T1), all the very-low-income adolescents from the 6th to the 13th grade who were attending the centers were invited to take part to the study $(n=306)$. Five minors refused, and three others abandoned the survey during the compilation. Therefore 298 participants completed the online survey in the first wave of data collection. Bullying, victimization, school achievement, peer acceptance and friendship were assessed at time 1 . At the second wave (time 2, T2), the questionnaires of bullying and victimization were administered again. By the time of this second wave, 49 of the participants were no longer attending the educational centres for various reasons (e.g. their families had moved house), so they did not complete the survey and were therefore excluded from the data analyses. Overall, we obtained a response rate of $97.4 \%$ at the first wave, and of $81.4 \%$ at the second wave. The high response rate at time 1 was probably a result of the positive climate in the educational centres, and it was also in accordance with recent studies conducted on Italian adolescents (Bianchi et al., 2020). The attrition between waves was similar to what obtained in previous longitudinal studies on adolescents (Van der Vorst et al., 2006). 
Missing data were not present in our database, because the online survey was set up with mandatory answers to all questions. Univariate analyses of variance were also performed on the baseline data, in order to detect possible differences on the study variables between included and excluded participants. Peer friendship, $F(1,298)=4.46, p=0.02$, and school achievement, $F(1,298)=10.16, p=0.002$, were higher in participants included in our study (vs. dropouts), but the effect sizes of these differences were negligible (friendship: Cohen's $d=0.18$ ) and small (school achievement: Cohen's $d=0.27$ ). The final sample consisted of 249 very-low-income early to late adolescents attending from the 6th to the 13th grade $\left(M_{\text {age }}=12.76 ; S D_{\text {age }}=2.34 ; 41.8 \%\right.$ girls $)$, with 156 early adolescents aged until $13\left(M_{\text {age }}=11.26 ; S D_{\text {age }}=1.35 ; 41 \%\right.$ girls $)$, and 93 middle to late adolescents aged 14 or above $\left(M_{\text {age }}=15.29 ; S D_{\text {age }}=1.17 ; 43 \%\right.$ girls $)$.

The immigrant participants in our study were the $19.3 \%$ of the final sample $(n=48)$, with 25 first generation and 23 second generation immigrants, corresponding to the percentage of immigrant minors attending public schools in Italy, as reported in national reports (ISMU, 2020; MIUR, 2019). The ethnic origin, familial language and age of arrival in Italy for first generation immigrants have not been investigated for privacy reasons. However, the national reports indicate that immigrant students in Italian schools are predominantly from other European countries and North Africa, with a prevalence around 45\% for Romanian, Albanian, and Moroccan students (MIUR, 2019). The researchers had previously ascertained that all immigrant minors in the study attended the school since the beginning of the current school year, and were able to autonomously understand the selfreport questionnaires, which were administered in Italian. This study and its procedures were in line with the institutional and national ethical standards and with the 1964 Helsinki declaration and its later amendments.

\section{Measures}

\section{Socio-Demographic Information}

Information was collected on the biological sex, age, country of birth of the participants and country of birth of their parents. Age measured at the baseline was then recoded in two groups, according to the categories adopted by previous studies (Valkenburg et al., 2011). Thus, the participants aged 13 or under, were classified as "early adolescents"; while those aged 14 or above, were classified as "middle to late adolescents". Data about country of birth were categorized in accordance with the criteria suggested by the Organization for Economic Co-Operation and Development (2014), so that minors born in a foreign country, and minors born in the host country to foreign-born parents were considered as immigrants. Biological sex $(0=$ girls; $1=$ boys $)$, age $(0=$ early adolescents; $1=$ middle to late adolescents), and immigrant background ( $0=$ natives; $1=$ immigrants $)$ were coded as dummy variables.

\section{School Achievement}

Following the procedure adopted in previous research (Niepel et al., 2014), school achievement was measured on the basis of self-reported school grades at the end of the previous school term. For each participant, a mean score was computed on the basis of the reported 
grades in mathematics and Italian language, the two most important subjects in Italian schools. The grades in our sample ranged from 4 to 10 , with marks of $\geq 6$ indicating a satisfactory level. Previous studies (e.g. Dickhäuser \& Plenter, 2005) have demonstrated the adequacy of self-reported school grades as indicators of school achievement.

\section{Peer Acceptance and Friendship}

The Classmate Social Isolation Questionnaire for adolescents (CSIQ-A; Cavicchiolo et al., 2019) was used to assess two dimensions of the relationships with classmates: Acceptance, which measured the self-reported number of classmates with whom participants have good relationships at school (4 items; sample item: "How many of your classmates do you chat with?"); and Friendship, which measured the self-reported number of classmates with whom participants have positive relationships also outside the context of school (4 items; sample item: "How many of your classmates do you go out with, to have some fun?"). Responses were rated on a 5 point-Likert scale $(1=$ none; $2=$ very few; $3=$ some; $4=$ many; $5=$ all), with higher scores indicating greater levels of perceived acceptance and friendship with classmates. The good psychometric properties of the scale had already been demonstrated in previous studies (Alivernini \& Manganelli, 2016; Cavicchiolo et al., 2019), and good reliability scores also emerged in our study (Cronbach's alpha of 0.79 for Acceptance and of 0.84 for Friendship).

\section{Bullying and Victimization}

Two questionnaires about bullying and victimization (Alivernini, Manganelli et al., 2019d) were administered to investigate different forms of bullying (verbal, physical, and relational) in the last school year, declined on the two dimensions of bullying perpetration (4 items; sample item: "This school year how often have you bullied/hassled other students at school by teasing them?"), and victimization (4 items; sample item: "This school year how often have other students bullied/hassled you at school by teasing you?"). The participants rated their answers on a 4-point Likert scale ( $1=$ never; $2=$ now and then; $3=$ weekly; $4=$ daily), with higher scores indicating more frequent bullying and victimization at school. The two scales have showed good psychometric properties on both native and immigrant students (Alivernini, Manganelli et al., 2019d), and their good reliability scores were also confirmed in our sample (Bullying reached Cronbach's alpha of 0.82 both at T1 and at T2; Victimization obtained alpha values of 0.83 at $\mathrm{T} 1$ and of 0.86 at $\mathrm{T} 2$ ).

\section{Data Analysis}

Statistical analyses were performed by using version 8.0 of the statistical modelling software programme MPLUS (Muthén, \& Muthén, 2017). Bivariate correlations and descriptive statistics were computed for the main study variables. A set of univariate analyses of variance (ANOVA) was performed on study variables to detect possible differences related to age (early vs. middle to late adolescence) and to immigrant background (natives vs. immigrants). A structural model was then tested on the general sample, using the Maximum Likelihood estimator. The baseline levels of peer acceptance and peer friendship were defined as statistical predictors of school bullying and 
victimization at $\mathrm{T} 2$, while controlling for their corresponding baseline levels. Biological sex and school achievement measured at T1 were also controlled as covariates. Finally, bullying and victimization at time 2 were set to correlate.

A first series of multigroup analyses was then conducted on the two age groups, to ascertain the existence of possible age differences in the parameters of the model between early and middle to late adolescence. Then, a second series of multigroup analyses were conducted with immigrant background as a grouping variable, in order to verify whether the model differed between natives and immigrants. The multigroup analyses were performed following a procedure suggested in previous studies (Matthews, 2017). Two versions of each model were tested: in the first version, all parameters were allowed to vary freely between groups (early vs. middle to late adolescents; immigrants vs. natives); in the second version, all parameters were set to be equal across groups. Then, a $\chi^{2}$ difference test was performed in order to determine if the unconstrained model explained the data significantly better than the totally constrained model. When a significant difference emerged, independent Wald $\chi^{2}$ difference tests were subsequently applied to verify which specific parameters significantly varied between groups (Kodde $\&$ Palm, 1986). An adjusted model was finally tested, in which only the significant paths emerged by the Wald $\chi^{2}$ tests were allowed to vary freely between groups, and this adjusted model was compared with the more conservative constrained model.

All of the measured constructs were entered into the models as observed variables for conserving statistical power due to our relatively small sample size. Goodness of fit of the models was assessed with the chi-square test statistic and the following fit indices: the Comparative Fit Index (CFI) and the Tucker-Lewis index (TLI), that are expected to be $\geq 0.90$ in an acceptable model fit (Hu \& Bentler, 1999); as well as the Root Mean Square Error of Approximation (RMSEA) and the Standardized Root Mean Square Residual (SRMR), expected to be $\leq 0.05$ in an acceptable fit (Kaplan, 2000).

\section{Results}

Descriptive statistics on the study variables are reported in Table 1. Results from ANOVA analyses yielded a significant age difference on school achievement, $F(1$, $248)=21.30, p<0.001$, with early adolescents reporting significantly higher school grades (vs. middle to late adolescents). About immigrant background, significant differences emerged on peer friendship, $F(1,248)=6.99, p=0.009$, that was significantly higher in natives (vs. immigrants), and on bullying victimization, $F(1,248)=5.02$, $p=0.03$, that conversely was higher for immigrants (vs. natives) (see Table 1). Bivariate Pearson's correlations on study variables are reported in Table 2.

The general model obtained a good fit to the data: $\chi^{2}(2)=2.98, p=0.22$; RMSEA $=0.04$; $\mathrm{CFI}=0.99$; TLI $=0.96$; $\mathrm{SRMR}=0.02$. The results of the model explained $20.7 \%$ of variance for bullying $(p<0.001)$, and $27.6 \%$ of variance for victimization $(p<0.001)$. Peer friendship negatively and significantly predicted both bullying and victimization, while non-significant associations emerged for peer acceptance, biological sex, and school achievement. Moreover, both bullying and victimization were predicted by their baseline levels and were positively correlated to each other. The statistics of the model are shown in Fig. 1. 


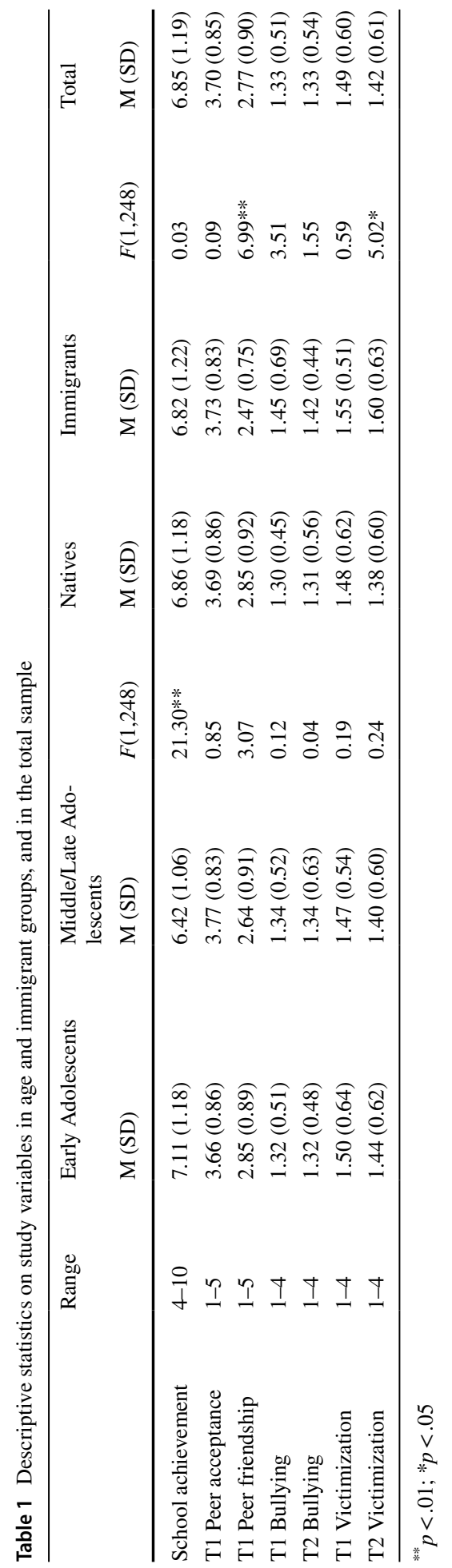




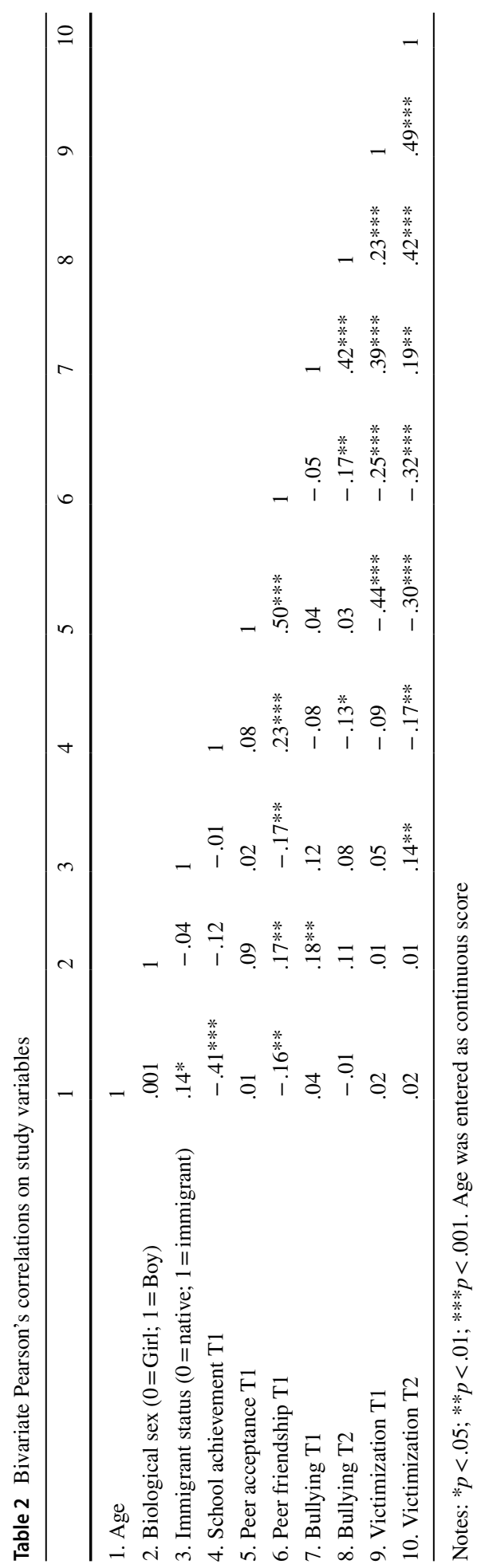


The first multigroup analysis tested the possible differences in the model across the two age groups. The first model, in which all the parameters were allowed to vary between the two age groups, obtained an acceptable fit to the data: $\chi^{2}(4)=5.57, p=0.23$; $\mathrm{RMSEA}=0.05 ; \mathrm{CFI}=0.99 ; \mathrm{TLI}=0.94 ; \mathrm{SRMR}=0.03$. However, the second model, in which all the parameters were constrained to be equal across age groups, also fitted the data well: $\chi^{2}(15)=11.02, p=0.75$; RMSEA $=0.000 ; \mathrm{CFI}=1.00$; TLI $=1.04$; SRMR $=0.06$. The Chi-square difference test conducted on the two models showed that the unconstrained model was not significantly different from the totally constrained model, $\Delta \chi^{2}(11)=5.45$, $p=0.90$, indicating that the model parameters did not vary between the age groups.

The second multi-group analysis was conducted allowing all the parameters to vary between the groups of natives and immigrants, and a good fit to the data was obtained: $\chi^{2}(4)=2.37, p=0.67 ; \mathrm{RMSEA}=0.000 ; \mathrm{CFI}=1.00 ; \mathrm{TLI}=1.06 ; \mathrm{SRMR}=0.02$. Another model was then tested constraining all the parameters to be equal across immigrant and native groups, but the fit to the data was worse: $\chi^{2}(15)=24.29, p=0.06$; RMSEA $=0.07$; $\mathrm{CFI}=0.95 ; \mathrm{TLI}=0.91 ; \mathrm{SRMR}=0.09$. The subsequent Chi-square comparison showed that constraining the model's parameters significantly worsened the fit indexes: $\Delta \chi^{2}$ $(11)=21.92, p=0.02$. Then, separate Wald $\chi^{2}$ tests were conducted in order to verify which specific parameters significantly differed across the groups. The path from school achievement to victimization, Wald $\chi^{2}(1)=5.59, p=0.02$, and the path from the baseline victimization level to victimization, Wald $\chi^{2}(1)=4.22, p=0.04$, turned out to be significantly different between immigrants and natives. The path from peer acceptance to bullying also approached significance, Wald $\chi^{2}(1)=3.25, p=0.07$. Thus, an adjusted model was tested in which only the three above-mentioned parameters were allowed to vary freely across the groups. This model obtained an excellent fit: $\chi^{2}(12)=8.82, p=0.71$; RMSEA $=0.000$; $\mathrm{CFI}=1.00$; $\mathrm{TLI}=1.04$; $\mathrm{SRMR}=0.05$, and described the data significantly better the totally constrained model: $\Delta \chi^{2}(2)=15.47, p=0.001$.

The final adjusted model accounted for $16.1 \%$ of variance for bullying $(p<0.001)$ and $25.7 \%$ of variance for victimization $(p<0.001)$ in the native group, while in the immigrant group the explained variance was $34 \%$ for bullying $(p<0.001)$, and $47.3 \%$ for victimization

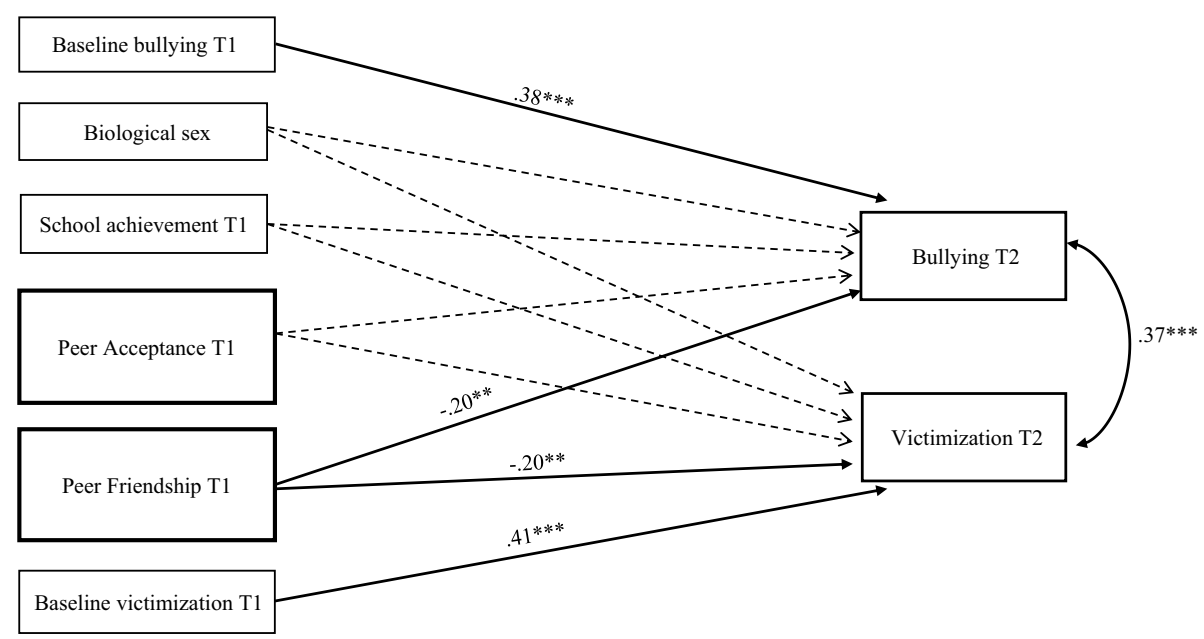

Fig. 1 General model. Notes: Parameters estimates are standardized. Dashed lines represent non-significant relationships. * $p<.05 ; * * p<.01 ; * * * p<.001$ 
$(p<0.001)$. The results indicated that peer acceptance was a positive predictor of bullying for natives (beta $=0.15, p=0.04$ ), but not for immigrants (beta $=-0.05, p=0.68$ ), whereas school achievement negatively predicted victimization among natives (beta $=-0.14$, $p=0.02$ ) but not among immigrants (beta $=0.09, p=0.37$ ). Moreover, the baseline level of victimization positively predicted victimization at $\mathrm{T} 2$ in both groups, but the weight of this relation was significantly stronger for immigrants (beta $=0.61, p<0.001)$ than for natives (beta $=0.35, p<0.001$ ). In both groups, peer friendship negatively predicted bullying and victimization, controlling for the effects of the corresponding baseline levels, and of biological sex and school achievement. Finally, bullying and victimization were positively correlated in both groups. The results of the adjusted model are presented in Fig. 2.

\section{Discussion}

The present study examined the prospective relationships of peer acceptance and friendship with bullying and victimization at school in a population of very-low-income native and immigrant adolescents. Very-low-income minors constitute a high-risk group for bullying and victimization (Tippett \& Wolke, 2014), and may specifically benefit from peer relationships at school, due to their lack of familial resources (Chaudry \& Wimer, 2016). However, very few studies have focused exclusively on the very-low-income population, due to the difficulties in reaching these students in longitudinal research, and the precise effects of poverty on bullying are still unclear (Tippett \& Wolke, 2014). Thus, our study is the first attempt to identify which particular bullying patterns may characterize the population of very-low-income adolescents. To our knowledge, this is also the first study to distinguish the different contributions of acceptance and friendship in their prospective associations with bullying dynamics, and to hypothesize specific patterns for immigrant students.

Our results showed that peer friendship, but not peer acceptance, negatively predicted both bullying and victimization at school in native as well as immigrant very-low-income

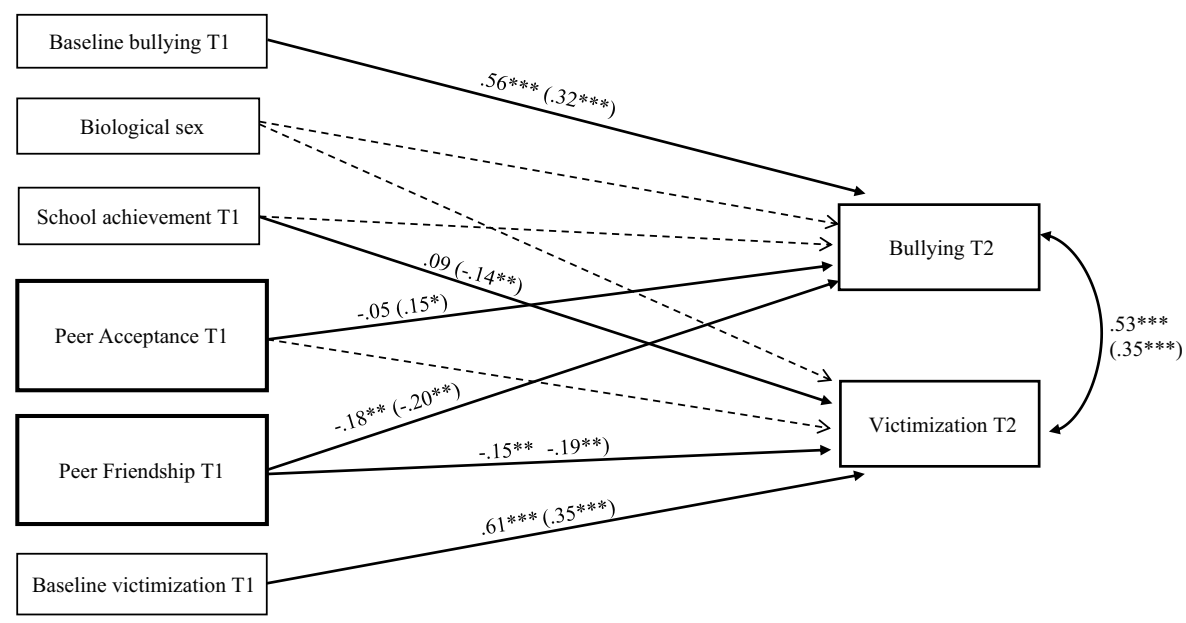

Fig. 2 Multi-group adjusted model for immigrants and natives. Notes: Parameters estimates are standardized. Estimates for natives are reported in brackets, estimates for immigrants are outside brackets. Dashed lines represent non-significant relationships. $* p<.05 ; * * p<.01 ; * * * p<.001$ 
students. Our findings provide support for the friendship protection hypothesis (Boulton et al., 1999; Kendrick et al., 2012), suggesting that very-low-income adolescents benefit particularly from friendships with their classmates, which reduce not only the likelihood of being victimized at school, but also that of enacting bullying behaviors against their peers. According to previous findings (Antonopoulou et al., 2019), supportive and reciprocal friendships are crucially important for psychosocial adjustment during adolescence. The quality of friendship may prevent both victimization and bullying in early adolescents (Kendrick et al., 2012; Kochel et al., 2015). Our study has confirmed these data and expanded them to the specific population of very-low-income adolescents, shedding a first light on the positive effects of peer friendship within this vulnerable group. Minors living in very disadvantaged families are more likely to be deprived of parental support (Chaudry \& Wimer, 2016; Conger et al., 2010), and so the role of their peers could be more important for their positive adjustment, in comparison with less disadvantaged students, constituting one of their few sources of social support. The positive effects of reciprocal friendships on self-esteem, self-confidence, and relational competence (Antonopoulou et al., 2019) could help very-low-income students to become more effective and cooperative in their social relationships, making them less prone to be victims, and less likely to enact bullying behaviors, despite the vulnerability deriving from their family environments. Moreover, having several friends in the classroom may discourage bullies from attacking these students, since they could be defended by their peers (Veenstra et al., 2010). These adolescents can also be more focused on their friendships-more highly valued due to the low emotional support they experience in their families - and can be less interested in attaining group achievement goals (Bardach et al., 2020), thereby consistently reducing their bullying behaviors.

On the other hand, we found no support for the hypothesis that acceptance might play a protective role against bullying and victimization. There have been contrasting results in the literature on the role of peer acceptance (Kochel et al., 2015; Mapes et al., 2020; Pouwels et al., 2016), and our findings suggest that, considering the simultaneous effects of acceptance and friendship, it is friendship that explains the greater variability in bullying dynamics. Peer acceptance by itself turned out to be ineffective in protecting very-lowincome students from victimization and bullying behaviors at school. However, this could be a very specific pattern for very-low-income minors, since the overall impact of poverty could annul the positive effects of peer acceptance, that we would expect in the general population (Cook et al., 2010). In the case of severe social disadvantage and unsupportive family environments, mere acceptance at school might be insufficient to protect these minors from negative outcomes, whereas the deep emotional ties that characterize friendships could be an important relational resource during the adolescent development.

Conversely, the peer acceptance at school emerged as a positive predictor for school bullying only in native, but not in immigrant students. This effect seems to be in line with the studies on social dominance of bullies (Reijntjes et al., 2016), who can be oriented towards gaining a dominant status in the peer group through their aggressive behavior. Our model suggests that native bullies are characterized by high levels of peer acceptance, but low levels of friendship, a result that supports previous studies, according to which bullies are very popular but not really liked by their schoolmates (Pouwels, et al., 2016). Our findings also indicate that peer acceptance is not such a significant factor for immigrant students, who are not likely to bully others as an affirmation of their status among their peers. As suggested by the very limited evidence on bullying among immigrant minorities (Albdour \& Krouse, 2014; Fandrem et al., 2009; 
Strohmeier et al., 2012), these minors tend to enact bullying as a reaction to perceived social exclusion, rather than to affirm their dominance among their peers.

As regard school achievement, our findings indicate that school marks are negatively related to victimization at school in native very-low-income students, but not in immigrants. This evidence can be interpreted in accordance with previous literature on the association between suffering victimization and having low academic performance (Ripski \& Gregory, 2009). Our findings suggest that low school achievement could be an additional factor of vulnerability for very-low-income natives: low school grades may be indicators of cognitive or learning difficulties, or other general conditions of vulnerability, which can prompt aggressions by bullies. However, this did not apply to immigrants in our study, who had a very specific pattern of victimization, regardless of their levels of academic achievement. As suggested by other studies on racial bullying (Caravita et al., 2020; Palladino et al., 2020), immigrant students are victimized specifically for their ethnic diversity, rather than for other factors of vulnerability.

Biological sex, controlled for in our model, was not a significant predictor of bullying and victimization. Previous research has suggested that gender and biological sex differences in bullying depend on a range of contextual factors (Espelage et al., 2004). However, the overall effect of poverty in our sample may have cancelled out the differences related to biological sex which were present in studies on the general population (Cook et al., 2010). As regard age, previous studies (Hymel \& Swearer, 2015; Scheithauer et al., 2006) have suggested that school bullying peaks during middle school and then decrease during high school years, but our findings have added to the literature by indicating that the relationships of peer acceptance and friendship with bullying and victimization did not vary with age, showing the same patterns both in early and in middle to late adolescents. This result could however be due to the overall effect of poverty, that provides our sample with a very specific functioning which not appear to vary during development.

As regards persistence, as we expected, both bullying and victimization were positively predicted by their prior baseline levels. However, our findings indicated that the persistence of victimization through time was significantly stronger-almost doublefor immigrants than for natives, suggesting that immigrant students are more at risk of being subject to long-term dynamics of victimization at school, with detrimental effects on their wellbeing and school adjustment.

Finally, our results showed that bullying and victimization were positively related to each other, with moderate to large correlations, both in native and immigrant very-lowincome students. Within the group of very-low-income students, bullying and victimization behaviors appear to overlap to some extent, and they could therefore be considered as two closely related facets of a same phenomenon in this population.

\section{Limitations and Conclusions}

The present study shed light on the protective role of peer relationships at school for very-low-income adolescents, disentangling the two different effects of peer acceptance and friendship. Friendship with classmates turned out to contrast the development of bullying perpetration and victimization over time, both in immigrant and in native students, and across different age groups. Peer acceptance at school instead was not related with victimization in very-low-income minors but, only for native students, it was a risk factor increasing bullying behaviors. Moreover, low school achievement was a risk 
factor for victimization only for native students. Finally, for immigrant adolescents, victimization was significantly more likely to persist over time in comparison to natives.

This study is not exempt by some limitations: first, our data was collected in Italy, a very interesting country for studying the immigrant development, due to its steadily increasing population of immigrant minors (ISMU, 2020). Nevertheless, further research will need to be conducted in order to generalize our findings to other cultural contexts. Second, the usual limitations of observational studies apply to our findings, and great caution should be made in interpreting the model parameters causally, even though we adopted a two-wave design. Third, our sample size is not large in reason of the difficulty to contact such a specific population in long-term studies, and immigrant participants are the $19 \%$ of the total sample, as expectable in line with the overall percentage of immigrant students in Italian schools (ISMU, 2020; MIUR, 2019). Therefore our sample constitutes a good representation of the very-low-income immigrant and native adolescents in Italy, however future studies would be desirable to replicate our findings, in order to overcome the limitations of necessary small sample sizes.

Despite these limits, our study is an innovative contribution to the field of research on bullying in vulnerable populations, as it is one of the first studies to simultaneously explore the effects of classmate acceptance and friendship in the development of bullying dynamics, in very-low-income native and immigrant adolescents. It is particularly important to study the possible protective role of peer relationships in very-low-income adolescents, due to the lack of support for these minors in their family environments. Our findings thus provide specific suggestions for prevention, education and further research. Future developments of our research should explore the quality and characteristics of peer relationships which can specifically protect very-low-income minors. For example, it would be worth to investigate if having same-sex or other-sex friendships can make the difference. It would be also important to understand if inter-ethnic and intra-ethnic friendships in the class group can have different roles in preventing bullying and victimization for immigrants, rather than for natives. Our results should hopefully be confirmed in longitudinal researches, aimed to explore the possible long-term stability of the significant patterns emerged.

Regarding prevention and intervention, most anti-bullying programs adopt the methods of peer mentoring and peer support to actively contrast bullying incidents at school (Cowie, 2011; Tzani-Pepelasi et al., 2019), but our findings can provide new insights to strengthen anti-bullying programs, by encouraging and actively building friendship networks in the school context, in which specifically including most vulnerable individuals, such as immigrant and very-low-income students. Moreover, our results provide evidence for the greater vulnerability of immigrant students to long-lasting dynamics of victimization, suggesting that victimized immigrant minors require specific attention by teachers and professionals, and should be supported with specially targeted interventions.

Funding Open access funding provided by Università degli Studi di Salerno within the CRUI-CARE Agreement. This research did not receive any funding.

Availability of Data and Material (Data Transparency) All authors are responsible for data transparency.

Code Availability (Software Application or Custom Code) Not applicable.

\section{Declarations}


Ethical Approval All procedures performed in studies involving human participants were in accordance with the ethical standards of the institutional and national research committee and with the 1964 Helsinki declaration and its later amendments or comparable ethical standards.

Informed Consent Informed consent was obtained from all individual participants included in the study.

Conflict of interest The authors declare that they have no conflict of interest.

Open Access This article is licensed under a Creative Commons Attribution 4.0 International License, which permits use, sharing, adaptation, distribution and reproduction in any medium or format, as long as you give appropriate credit to the original author(s) and the source, provide a link to the Creative Commons licence, and indicate if changes were made. The images or other third party material in this article are included in the article's Creative Commons licence, unless indicated otherwise in a credit line to the material. If material is not included in the article's Creative Commons licence and your intended use is not permitted by statutory regulation or exceeds the permitted use, you will need to obtain permission directly from the copyright holder. To view a copy of this licence, visit http://creativecommons.org/licenses/by/4.0/.

\section{References}

Ackerman, B. P., Brown, E. D., \& Izard, C. E. (2004). The relations between persistent poverty and contextual risk and children's behavior in elementary school. Developmental Psychology, 40(3), 367-377.

Albdour, M., \& Krouse, H. J. (2014). Bullying and victimization among African American adolescents: A literature review. Journal of Child and Adolescent Psychiatric Nursing, 27(2), 68-82.

Alivernini, F., Cavicchiolo, E., Girelli, L., Lucidi, F., Biasi, V., Leone, L., et al. (2019a). Relationships between sociocultural factors (gender, immigrant and socioeconomic background), peer relatedness and positive affect in adolescents. Journal of Adolescence, 76(August), 99-108.

Alivernini, F., Cavicchiolo, E., \& Manganelli, S. (2019b). Brothers, ants or thieves: Students' complex attitudes towards immigrants and the role of socioeconomic status and gender in shaping them. Social Psychology of Education, 22(3), 629-647.

Alivernini, F., Cavicchiolo, E., Manganelli, S., Chirico, A., \& Lucidi, F. (2019c). Support for autonomy at school predicts immigrant adolescents' psychological well-being. Journal of Immigrant and Minority Health, 21(4), 761-766.

Alivernini, F., Manganelli, S., Cavicchiolo, E., \& Lucidi, F. (2019d). Measuring bullying and victimization among immigrant and native primary school students: Evidence from Italy. Journal of Psychoeducational Assessment, 37(2), 226-238.

Alivernini, F., Manganelli, S., \& Lucidi, F. (2016). Personal and classroom achievement goals: Their structures and relationships. Journal of Psychoeducational Assessment, 36(4), 354-365.

Antonopoulou, K., Chaidemenou, A., \& Kouvava, S. (2019). Peer acceptance and friendships among primary school pupils: Associations with loneliness, self-esteem and school engagement. Educational Psychology in Practice, 35(3), 339-351.

Attree, P. (2006). The social costs of child poverty: A systematic review of the qualitative evidence. Children \& Society, 20(1), 54-66.

Bao, J., Li, H., Song, W., \& Jiang, S. (2020). Being bullied, psychological pain and suicidal ideation among Chinese adolescents: A moderated mediation model. Children and Youth Services Review, 109, 104744.

Bardach, L., Graf, D., Yanagida, T., Kollmayer, M., Spiel, C., \& Lüftenegger, M. (2020). Gendered pathways to bullying perpetration via social achievement goals-mediating effects of sense of belonging and non-inclusive group norms. Journal of School Violence, 19(2), 248-263.

Berndt, T. J. (2002). Friendship quality and social development. Current Directions in Psychological Science, 11(1), 7-10.

Bianchi, D., Lonigro, A., Baiocco, R., Baumgartner, E., \& Laghi, F. (2020). Social anxiety and peer communication quality during adolescence: The interaction of social avoidance, empathic concern and perspective taking. Child \& Youth Care Forum, 49(6), 853-876.

Bierman, K. L. (2004). The Guilford series on social and emotional development. Peer rejection: Developmental processes and intervention strategies. . Guilford. 
Birkeland, M. S., Breivik, K., \& Wold, B. (2014). Peer acceptance protects global self-esteem from negative effects of low closeness to parents during adolescence and early adulthood. Journal of Youth and Adolescence, 43(1), 70-80.

Bollmer, J. M., Milich, R., Harris, M. J., \& Maras, M. A. (2005). A friend in need-The role of friendship quality as a protective factor in peer victimization and bullying. Journal of Interpersonal Violence, 20, 701-712.

Boulton, M. J., Trueman, M., Chau, C., Whitehand, C., \& Amatya, K. (1999). Concurrent and longitudinal links between friendship and peer victimization: Implications for befriending interventions. Journal of Adolescence, 22(4), 461-466.

Bradshaw, C. P., Sawyer, A. L., \& O’Brennan, L. M. (2009). A social disorganization perspective on bullying-related attitudes and behaviors: The influence of school context. American Journal of Community Psychology, 43(3-4), 204-220.

Bronfenbrenner, U. (1994). Ecological models of human development. In T. Husen \& T. N. Postlethwaite (Eds.), The international encyclopedia of education. (2nd ed., pp. 1643-1647). New York: Elsevier Sciences.

Caravita, S. C., Stefanelli, S., Mazzone, A., Cadei, L., Thornberg, R., \& Ambrosini, B. (2020). When the bullied peer is native-born vs. immigrant: A mixed-method study with a sample of native-born and immigrant adolescents. Scandinavian Journal of Psychology, 61(1), 97-107.

Cavicchiolo, E., Girelli, L., Lucidi, F., Manganelli, S., \& Alivernini, F. (2019). The Classmates Social Isolation Questionnaire for Adolescents (CSIQ-A): Validation and invariance across immigrant background, gender and socioeconomic level. Journal of Educational, Cultural and Psychological Studies (ECPS Journal), 19, 163-174.

Cavicchiolo, E., Manganelli, S., Bianchi, D., Biasi, V., Lucidi, F., Girelli, L., et al. (2020). Social inclusion of immigrant children at school: The impact of group, family and individual characteristics, and the role of proficiency in the national language. International Journal of Inclusive Education.

Celia, G. (2020). Les styles narratifs du groupe comme indicateurs de changement [The narrative styles of the group as indicators of change]. Revue de psychothérapie psychanalytique de groupe, 74(1), $157-168$.

Chai, L., Xue, J., \& Han, Z. (2020). School bullying victimization and self-rated health and life satisfaction: The mediating effect of relationships with parents, teachers, and peers. Children and Youth Services Review, 105281.

Chaudry, A., \& Fortuny, K. (2010). Children of immigrants: Economic well-being (Brief No. 4). Washington, DC: Urban Institute. Accessed online on February 2021. https://www.fcd-us.org/assets/ 2016/04/TUI-Children-of-Immigrants-Economic-Well-Being.pdf

Chaudry, A., \& Wimer, C. (2016). Poverty is not just an indicator: The relationship between income, poverty, and child well-being. Academic Pediatrics, 16(3), S23-S29.

Chaux, E., Molano, A., \& Podlesky, P. (2009). Socio-economic, socio-political and socio-emotional variables explaining school bullying: A country-wide multilevel analysis. Aggressive Behavior, 35(6), 520-529.

Chen, E., Martin, A. D., \& Matthews, K. A. (2006). Understanding health disparities: The role of race and socioeconomic status in children's health. American Journal of Public Health, 96(4), $702-708$.

Colarossi, L. G., \& Eccles, J. S. (2003). Differential effects of support providers on adolescents' mental health. Social Work Research, 27(1), 19-30.

Conger, R. D., Conger, K. J., \& Martin, M. J. (2010). Socioeconomic status, family processes, and individual development. Journal of Marriage and Family, 72(3), 685-704.

Cook, C. R., Williams, K. R., Guerra, N. G., Kim, T. E., \& Sadek, S. (2010). Predictors of bullying and victimization in childhood and adolescence: A meta-analytic investigation. School Psychology Quarterly, 25(2), 65-83.

Cowie, H. (2011). Peer support as an intervention to counteract school bullying: Listen to the children. Children \& Society, 25(4), 287-292.

Cozzolino, M., Vivo, R., Girelli, L., Limone, P., \& Celia, G. (2020) The Evaluation of a Mind-Body Intervention (MBT-T) for Stress Reduction in Academic Settings: A Pilot Study. Behavioral Sciences, $10(8), 124$.

Cui, K., \& To, S. M. (2019). Migrant status, social support, and bullying perpetration of children in mainland China. Children and Youth Services Review, 107, 104534.

de Bruyn, E. H., Cillessen, A. H., \& Wissink, I. B. (2010). Associations of peer acceptance and perceived popularity with bullying and victimization in early adolescence. The Journal of Early Adolescence, 30(4), 543-566. 
Demaray, M. K., \& Malecki, C. K. (2003). Perceptions of the frequency and importance of social support by students classified as victims, bullies and bully/victims in an urban middle school. School Psychology Review, 32, 471-489.

Dickhäuser, O., \& Plenter, I. (2005). "Letztes Halbjahr stand ich zwei”. Zur Akkuratheit selbst berichteter Noten ["Last term I had a B". On the accuracy of self-reported school grades]. Zeitschrift für Pädagogische Psychologie, 19(4), 219-224.

Dietrich, L., \& Ferguson, R. F. (2020). Why stigmatized adolescents bully more: The role of self-esteem and academic-status insecurity. International Journal of Adolescence and Youth, 25(1), 305-318.

Domagala-Zysk, E. (2006). The significance of adolescents' relationships with significant others and school failure. School Psychology International, 27(2), 232-247.

Eslea, M., Menesini, E., Morita, Y., O’Moore, M., Mora-Merchán, J. A., Pereira, B., \& Smith, P. K. (2004). Friendship and loneliness among bullies and victims: Data from seven countries. Aggressive Behavior: Official Journal of the International Society for Research on Aggression, 30(1), 71-83.

Espelage, D. L., Holt, M. K., \& Henkel, R. R. (2003). Examination of peer group contextual effects on aggressive behavior during early adolescence. Child Development, 74, 205-220.

Espelage, D. L., Mebane, S. E., \& Swearer, S. M. (2004). Gender differences in bullying: Moving beyond mean level differences. In Bullying in American schools (pp. 37-58). Routledge.

Espelage, D. L., \& Swearer, S. M. (2010). A social-ecological model for bullying prevention and intervention. In S. R. Jimerson, S. M. Swearer, \& D. L. Espelage (Eds.), Handbook of bullying in schools: An international perspective. (pp. 61-72). Routledge.

Ezzell, C. E., Swenson, C. C., \& Brondino, M. J. (2000). The relationship of social support to physically abused children's adjustment. Child Abuse \& Neglect, 24(5), 641-651.

Fandrem, H., Strohmeier, D., \& Roland, E. (2009). Bullying and victimization among native and immigrant adolescents in Norway: The role of proactive and reactive aggressiveness. The Journal of Early Adolescence, 29(6), 898-923.

Fanti, K. A., \& Kimonis, E. (2012). Bullying and victimization: The role of conduct problems and psychopathic traits. Journal of Research on Adolescence, 22, 617-631.

Farrington, D., \& Baldry, A. (2010). Individual risk factors for school bullying. Journal of Aggression, Conflict and Peace Research, 2(1), 4-16.

Flaspohler, P. D., Elfstrom, J. L., Vanderzee, K. L., Sink, H. E., \& Birchmeier, Z. (2009). Stand by me: The effects of peer and teacher support in mitigating the impact of bullying on quality of life. Psychology in the Schools, 46(7), 636-649.

Foundation for Initiatives and Studies on Multi-Ethnicity, ISMU (2020). The Twenty-fifth Italian Report on Migrations 2019 (National Report). Retrieved online on August 2020 from https://www.ismu. org/the-twenty-fifth-italian-report-on-migrations-2019/

Gini, G., Pozzoli, T., \& Bussey, K. (2015). The role of individual and collective moral disengagement in peer aggression and bystanding: A multilevel analysis. Journal of Abnormal Child Psychology, 43(3), 441-452.

Girelli, L., Alivernini, A., Lucidi, F., Cozzolino, S., Savarese, G., Sibilio, M., \& Salvatore, S. (2018). Autonomy supportive contexts, autonomous motivation, and self-efficacy predict academic adjustment of first-year university students. Frontiers in Education, 3(95), 1-11.

Hall, J. A. (2019). How many hours does it take to make a friend? Journal of Social and Personal Relationships, 36(4), 1278-1296.

Hong, J. S., Choi, J., Espelage, D. L., Wu, C. F., Boraggina-Ballard, L., \& Fisher, B. W. (2020). Are children of welfare recipients at a heightened risk of bullying and peer victimization? Child \& Youth Care Forum. https://doi.org/10.1007/s10566-020-09587-w.

Hong, J. S., \& Espelage, D. L. (2012). A review of research on bullying and peer victimization in school: An ecological system analysis. Aggression and Violent Behavior, 17(4), 311-322.

Hong, J. S., Kim, D. H., Narvey, C., Piquero, A. R., deLara, E., \& Padilla, Y. C. (2020). Understanding the link between family economic hardship and children's bullying behavior. Youth \& Society. https://doi.org/10.1177/0044118X20932594.

Hong, J. S., Peguero, A. A., Choi, S., Lanesskog, D., Espelage, D. L., \& Lee, N. Y. (2014). Social ecology of bullying and peer victimization of Latino and Asian youth in the United States: A review of the literature. Journal of School Violence, 13, 315-338.

Hu, L. T., \& Bentler, P. M. (1999). Cutoff criteria for fit indexes in covariance structure analysis: Conventional criteria versus new alternatives. Structural Equation Modeling: A Multidisciplinary Journal, 6(1), 1-55.

Hymel, S., \& Swearer, S. M. (2015). Four decades of research on school bullying: An introduction. American Psychologist, 70, 293-299. 
Juvonen, J., \& Graham, S. (2014). Bullying in schools: The power of bullies and the plight of victims. Annual Review of Psychology, 65, 159-185. https://doi.org/10.1146/annur ev-psych-010213-115030.

Kaplan, D. (2000). Structural equation modelling. Foundations and extensions. Thousand Oaks: Sage.

Kendrick, K., Jutengren, G., \& Stattin, H. (2012). The protective role of supportive friends against bullying perpetration and victimization. Journal of Adolescence, 35(4), 1069-1080.

Kochel, K. P., Ladd, G. W., Bagwell, C. L., \& Yabko, B. A. (2015). Bully/victim Profiles' differential risk for worsening peer acceptance: The role of friendship. Journal of Applied Developmental Psychology, 41, 38-45.

Kodde, D., \& Palm, F. (1986). Wald criteria for jointly testing equality and inequality restrictions. Econometrica, 54(5), 1243-1248.

Lehman, B. (2014). Gender differences in bullying victimization: The role of academics and school context. Sociological Spectrum, 34(6), 549-570.

Malecki, C. K., \& Demaray, M. K. (2003). What type of support do they need? Investigating student adjustment as related to emotional, informational, appraisal, and instrumental support. School Psychology Quarterly, 18(3), 231.

Malecki, C. K., Demaray, M. K., Smith, T. J., \& Emmons, J. (2020). Disability, poverty, and other risk factors associated with involvement in bullying behaviors. Journal of School Psychology, 78, 115-132.

Mapes, A. R., Scafe, M., Mutignani, L. M., Hernandez Rodriguez, J., Pastrana, F. A., Gregus, S., Craig, J. T., \& Cavell, T. A. (2020). Liked by peers or liked by teachers: Differential patterns of bullying over time. Journal of School Violence, 19, 470-484.

Matthews, L. (2017). Applying multigroup analysis in PLS-SEM: A step-by-step process. In H. Latan \& R. Noonan (Eds.), Partial least squares path modeling. Cham: Springer.

Maynard, B. R., Vaughn, M. G., Salas-Wright, C. P., \& Vaughn, S. (2016). Bullying victimization among school-aged immigrant youth in the United States. Journal of Adolescent Health, 58(3), 337-344.

Menesini E., Nocentini A. (2015). Il bullismo a scuola. Come prevenirlo, come intervenire. [Bullying at school: How to prevent, how to intervene] Firenze: Giunti Scuola.

Menesini, E., \& Salmivalli, C. (2017). Bullying in schools: The state of knowledge and effective interventions. Psychology, Health \& Medicine, 22(1), 240-253.

Milione, A. (2011). Young immigrants at school: Inclusion and location of rights in Italy. Italian Journal of Sociology of Education, 3(2), 173-198.

Ministry of Education, Universities and Research [MIUR] (2019). Gli alunni con cittadinanza non italiana A.S. 2017/2018 [Students with non-Italian citizenship 2017-2018] Retrieved online on August 2020 from: https://miur.gov.it/documents/20182/250189/Notiziario+Stranieri+1718.pdf/78ab5 3c4-dd30-0c0f-7f40-bf22bbcedfa6?version $=1.2 \& \mathrm{t}=1562937526726$

Monopoli, W. J., Margherio, S. M., Evans, S. W., Xiang, J., Brickner, M. A., \& Langberg, J. M. (2020). Risk and protective factors for peer victimization in adolescents with ADHD. Journal of School Violence, 19(2), 234-247.

Muthén, L. K., \& Muthén, B. O. (2017). MPlus: Statistical analysis with latent variables-User's guide (Version 8). Los Angeles, CA.

Nansel, T. R., Overpeck, M., Pilla, R. S., Ruan, W. J., Simons-Morton, B., \& Scheidt, P. (2001). Bullying behaviors among US youth: Prevalence and association with psychosocial adjustment. JAMA, 285(16), 2094-2100.

National Institute of Statistics [ISTAT] (2020). Poverty in Italy Year 2019. Retrieved online on February 2021, https://www.istat.it/it/files//2020/07/REPORT_POVERTA_2019_eng.pdf

Niepel, C., Brunner, M., \& Preckel, F. (2014). Achievement goals, academic self-concept, and school grades in mathematics: Longitudinal reciprocal relations in above average ability secondary school students. Contemporary Educational Psychology, 39(4), 301-313.

Olsen, L. (2008). Made in America: Immigrant students in our public schools. New York, NY: The New Press.

Olweus, D. (1993). Bullying at school: What we know and what we can do. Oxford: Blackwell.

Organization for Economic Co-Operation and Development. (2014). PISA 2012 technical report. Programme for International Student Assessment, Organisation for Economic Co-Operation and Development Publishing. Retrieved online on August 2020 from: http://www.oecd.org/pisa/pisap roducts/PISA-2012-technical-report-final.pdf

Palladino, B. E., Nappa, M. R., Zambuto, V., \& Menesini, E. (2020). Ethnic bullying victimization in Italy: The role of acculturation orientation for ethnic minority adolescents with differing citizenship statuses. Frontiers in Psychology. https://doi.org/10.3389/fpsyg.2020.00499. 
Peguero, A. A. (2012). Schools, bullying and inequality: Intersecting factors and complexities with the stratification of youth victimization at school. Sociology Compass, 6, 402-412.

Peguero, A. A., \& Popp, A. M. (2012). Youth violence at school and the intersection of gender, race and ethnicity. Journal of Criminal Justice, 40, 1-9.

Peguero, A. A., Popp, A. M., \& Ko, D. J. (2011). Race, ethnicity, and school-based adolescent victimization. Crime and Delinquency, 61(3), 323-349.

Peguero, A. A., \& Williams, L. M. (2013). Racial and ethnic stereotypes and bullying victimization. Youth \& Society, 45, 545-564.

Pistella, J., Baumgartner, E., Laghi, F., Salvati, M., Carone, N., Rosati, F., \& Baiocco, R. (2020). Verbal, physical, and relational peer victimization: The role of immigrant status and gender. Psicothema, 32(2), 214-220.

Pistella, J., Zava, F., Sette, S., Baumgartner, E., \& Baiocco, R. (2020). Peer victimization, social functioning, and temperament traits in preschool children: The role of gender, immigrant status and sympathy. Child Indicators Research, 13, 2135-2156.

Plenty, S., \& Jonsson, J. O. (2017). Social exclusion among peers: The role of immigrant status and classroom immigrant density. Journal of Youth and Adolescence, 46(6), 1275-1288.

Pouwels, J. L., Lansu, T. A. M., \& Cillessen, A. H. N. (2016). Participant roles of bullying in adolescence: Status characteristics, social behavior, and assignment criteria. Aggressive Behavior, 42, 239-253.

Reijntjes, A., Vermande, M., Thomaes, S., Goossens, F., Olthof, T., Aleva, L., \& Van der Meulen, M. (2016). Narcissism, bullying, and social dominance in youth: A longitudinal analysis. Journal of Abnormal Child Psychology, 44, 63-74.

Ripski, M. B., \& Gregory, A. (2009). Unfair, unsafe, and unwelcome: Do high school students' perceptions of unfairness, hostility, and victimization in school predict engagement and achievement? Journal of School Violence, 8(4), 355-375.

Saarento, S., \& Salmivalli, C. (2015). The role of classroom peer ecology and bystanders' responses in bullying. Child Development Perspectives, 9(4), 201-205.

Scheithauer, H., Hayer, T., Petermann, F., \& Jugert, G. (2006). Physical, verbal, and relational forms of bullying among German students: Age trends, gender differences, and correlates. Aggressive Behavior: Official Journal of the International Society for Research on Aggression, 32(3), 261-275.

Seo, H. J., Jung, Y. E., Kim, M. D., \& Bahk, W. M. (2017). Factors associated with bullying victimization among Korean adolescents. Neuropsychiatric disease and treatment, 13, 2429-2435.

Smith, P. K., \& Brain, P. (2000). Bullying in schools: Lessons from two decades of research. Aggressive Behavior, 26, 1-9.

Smith, P. K., López-Castro, L., Robinson, S., \& Görzig, A. (2019). Consistency of gender differences in bullying in cross-cultural surveys. Aggression and Violent Behavior, 45, 33-40.

Strohmeier, D., Fandrem, H., \& Spiel, C. (2012). The need for peer acceptance and affiliation as underlying motive for aggressive behaviour and bullying others among immigrant youth living in Austria and Norway. Anales de Psicología, 28(3), 695-704.

Strohmeier, D., Kärnä, A., \& Salmivalli, C. (2011). Intrapersonal and interpersonal risk factors for peer victimization in immigrant youth in Finland. Developmental Psychology, 47(1), 248-258.

Suárez-Orozco, C., Suárez-Orozco, M., \& Todorova, I. (2008). Learning a new land: Immigrant students in American society. Cambridge, MA: Harvard University Press.

Tippett, N., \& Wolke, D. (2014). Socioeconomic status and bullying: A meta-analysis. American Journal of Public Health, 104(6), e48-e59.

Tzani-Pepelasi, C., Ioannou, M., Synnott, J., \& McDonnell, D. (2019). Peer support at schools: The buddy approach as a prevention and intervention strategy for school bullying. International Journal of Bullying Prevention, 1(2), 111-123.

Valkenburg, P. M., Sumter, S. R., \& Peter, J. (2011). Gender differences in online and offline self-disclosure in pre-adolescence and adolescence. British Journal of Developmental Psychology, 29(2), 253-269.

Van der Vorst, H., Engels, R. C., Meeus, W., \& Deković, M. (2006). Parental attachment, parental control, and early development of alcohol use: A longitudinal study. Psychology of Addictive Behaviors, 20(2), 107-116.

Van Noorden, T. H. J., Bukowski, W. M., Haselager, G. J. T., \& Cillessen, A. H. N. (2016). Disentangling the frequency and severity of bullying and victimization in the association with empathy. Social Development, 25, 176-192.

Vecchiato, T. (2015). Poverty in Italy and Generative Welfare Approach. In Theoretical and Empirical Insights into Child and Family Poverty (pp. 185-200). Cham: Springer. 
Veenstra, R., Lindenberg, S., Munniksma, A., \& Dijkstra, J. K. (2010). The complex relation between bullying, victimization, acceptance, and rejection: Giving special attention to status, affection, and sex differences. Child Development, 81(2), 480-486.

Vieno, A., Lenzi, M., Gini, G., Pozzoli, T., Cavallo, F., \& Santinello, M. (2015). Time trends in bullying behavior in Italy. Journal of school health, 85(7), 441-445.

Walsh, S. D., De Clercq, B., Molcho, M., Harel-Fisch, Y., Davison, C. M., Madsen, K. R., \& Stevens, G. W. (2016). The relationship between immigrant school composition, classmate support and involvement in physical fighting and bullying among adolescent immigrants and non-immigrants in 11 countries. Journal of Youth and Adolescence, 45(1), 1-16.

Woods, S., \& Wolke, D. (2004). Direct and relational bullying among primary school children and academic achievement. Journal of School Psychology, 42(2), 135-155.

Publisher's Note Springer Nature remains neutral with regard to jurisdictional claims in published maps and institutional affiliations. 